\title{
Utilização de biomassas como combustível na produção de cimento Portland
}

Gabriela Fernanda Moraes dos Santos

Barbara Ferreira Massanares

Alana Melo dos Santos

\section{Registro DOI: http://dx.doi.org/10.22280/revintervol12ed2.440}

\begin{abstract}
Resumo
O cimento é largamente utilizado nas construções civis de grande e pequeno porte em todo o mundo e sua produção é responsável pela grande emissão de diversos poluentes para o meio ambiente devido a queima de combustíveis fósseis na etapa de aquecimento dos fornos. Desta forma, grandes potências mundiais vêm estudando alternativas para minimizar os impactos ao meio ambiente relacionados a essa poluição. Uma metodologia que vem sendo explorada é a substituição da utilização de combustíveis fósseis no aquecimento dos fornos por combustíveis renováveis, como o carvão vegetal e as biomassas que possuam características físico-químicas semelhantes à do coque e do carvão mineral. $\mathrm{O}$ presente trabalho objetiva avaliar alguns tipos de biomassa origem agrícola de diversos segmentos que possam ser utilizadas como combustível ou parte do mesmo na produção de cimento Portland. A avaliação foi realizada com base no poder calorífico de cada biomassa, comparando-o com o do carvão mineral utilizado em fornos, bem como através de uma análise econômica e logística do material renovável. A coleta de dados foi realizada por meio de pesquisa bibliográfica em dissertações e artigos publicados em revistas e convenções, resultando em projeções satisfatórias da utilização de biomassas.
\end{abstract}

Palavras-chave: Biomassa. Poder calorífico. Produção cimento. Meio ambiente

Use of biomass as fuel in Portland cement production

\begin{abstract}
Cement is widely used in civil construction of large and small worldwide and its production is responsible for the large emission of various pollutants to the environment due to the burning of fossil fuels in the heating stage of the furnaces. That's way, great world powers have been studying alternatives to minimize the impacts to the environment related to this pollution. One methodology that has been explored is the replacement of the use of fossil fuels in furnace heating by renewable fuels, such as charcoal and biomasses that have physicochemical characteristics similar to coke and coal. The present work aims to evaluate some types of biomass agricultural sources of several segments that can be used as fuel or part of it in the production of Portland cement. The evaluation was carried out based on the calorific value of each biomass, comparing it with that of the mineral coal used in furnaces, as well as an economic and logistic analysis of the renewable material. Data collection was done through bibliographic research in dissertations and articles published in magazines and conventions, resulting in satisfactory projections of the use of biomasses.
\end{abstract}

Keywords: Biomass. Calorific value. Cement production. Environment. 


\section{Revinter}

Recebido em 24/04/2019 Aceito em 20/06/2019

\section{INTRODUÇÃO}

O cimento é largamente utilizado nas construções civis de grande e pequeno porte em todo o mundo. O processo de fabricação do cimento Portland consiste resumidamente em três etapas:

1) Mistura e moagem de matérias primas (calcário, britas de rochas, argilas);

2) Produção do clínquer em fornos que são aquecidos em torno de $1500^{\circ} \mathrm{C}$ utilizando como combustíveis produtos de origem fósseis. O clínquer é o produto da calcinação de calcário e argila, e é utilizado como matéria-prima para a produção de cimento, após moagem;

3) Moagem do cimento.

A produção deste cimento é responsável pela emissão de muitos poluentes para o meio ambiente. De acordo com dados fornecidos pela CSI (The Cement Sustainability Initiative) em 2002, esse ramo da indústria é responsável por 3\% das emissões mundiais de Gases de Efeito Estufa (GEE) e por aproximadamente $5 \%$ das emissões de $\mathrm{CO}_{2}$ (dióxido de carbono). Segundo a SINC (Sindicato Nacional da Indústria do Cimento), em seu relatório anual apresentando em 2010, as emissões provenientes da produção de cimento são 22.400 .000 toneladas de $\mathrm{CO}_{2}$, somente no ano de 2005.

Os fabricantes de cimento buscam combustíveis que otimizam os custos e a qualidade do produto e minimizam impacto ambiental (JACKSON, 1998; GRECO et al., 2004).

Desde a década de 1970, os resíduos de combustíveis foram utilizados na indústria de cimento para substituição parcial de combustíveis tradicionais (KARSTENSEN, 2004). Hoje, os combustíveis usados representam $20-70 \%$ da demanda total de energia em uma instalação de cimento (PCA, 2009).

Uma característica importante na análise de combustíveis é o poder calorífico, que simboliza a quantidade de calor obtido durante o processo de combustão, na unidade de caloria por grama (cal/g) ou quilocaloria por quilograma $(\mathrm{kcal} / \mathrm{kg})$, considerando-se seu estado sem a presença de umidade. O poder calorífico pode ser apresentado de duas formas: Poder Calorífico Superior (PCS) e Poder Calorífico Inferior (PCI). Ao classificá-lo, leva-se em conta se o calor liberado pela condensação da água de constituição da madeira (formada durante a combustão 
em razão da presença de hidrogênio na composição química elementar da madeira) é considerado. 
O PCI considera a quantidade de hidrogênio presente na amostra e, em geral, é a escolha preferida na análise de combustíveis, podendo ser calculado a partir do conhecimento do PCS, o qual é determinado através de calorímetros. Quanto maior o PCI, maior será a quantidade de energia produzida por massa da amostra. Portanto, se for possível utilizar uma biomassa que possui maior PCI em comparação com um combustível não renovável, menor será a massa na queima e menor será seu impacto ambiental.

O carvão vegetal é uma biomassa bastante explorada como alternativa para substituir o carvão mineral nos fornos e estudos sobre o uso de outros tipos biomassas - especificamente as de origem agrícola - são menos frequentes. Portanto, este trabalho procurou analisar o poder calorífico de biomassas deste segmento e sua viabilidade no uso nos fornos de produção de clínquer.

\section{EFEITOS E IMPACTOS AMBIENTAIS NO PROCESSO DE PRODUÇÃO DO CIMENTO}

Conforme dados fornecidos pela ABCP (Associação Brasileira de Cimento Portland), a partir dos anos 70, com o "milagre econômico", a indústria do cimento foi estimulada por vários projetos habitacionais e de infraestrutura. Com isso, em um período de 10 anos, o consumo deste material passou de 100 para $227 \mathrm{~kg}$ por habitante. A produção de cimento tem como etapa inicial a extração do calcário. Em seguida, o mesmo é moído com argila e outros materiais em menor quantidade, com o objetivo de conseguir um pó fino, chamado de farinha crua. Tal material é inserido em um forno rotativo, onde é aquecido até atingir a temperatura de $1500{ }^{\circ} \mathrm{C}$ e, em seguida, é resfriado por rajadas de ar. O material obtido após o resfriamento é o clínquer, sendo esta a matéria-prima para produção de cimento. O clínquer é misturado com gesso e outras adições com a ajuda de um moinho de cimento, com o objetivo de atingirem a granulometria ideal. Na produção, há uma grande demanda de energia térmica, tanto elétrica (funcionamento de moinhos, fornos rotativos, etc.) quanto na queima de combustíveis, geralmente de origem fóssil, como o coque de petróleo, carvão mineral e gás, no aquecimento de fornos rotativos para produção de clínquer.

De acordo com o relatório anual do Sindicato Nacional da Indústria do Cimento realizado no ano de 2012, ao analisar o gráfico apresentado na Figura 1, relativo à emissão média de $\mathrm{CO}_{2} \mathrm{em} \mathrm{kg}$ por tonelada de cimento podemos constatar que no ano de 2011 o Brasil 
é o país que apresenta menor emissão de $\mathrm{CO}_{2}$ (em torno de 500 a $600 \mathrm{~kg}$ de $\mathrm{CO}_{2} /$ tonelada de cimento) em comparação com os demais países e continentes estudados.

\section{Figura 1 - Emissão média de $\mathrm{CO}_{2}$ em kg/tonelada de cimento}

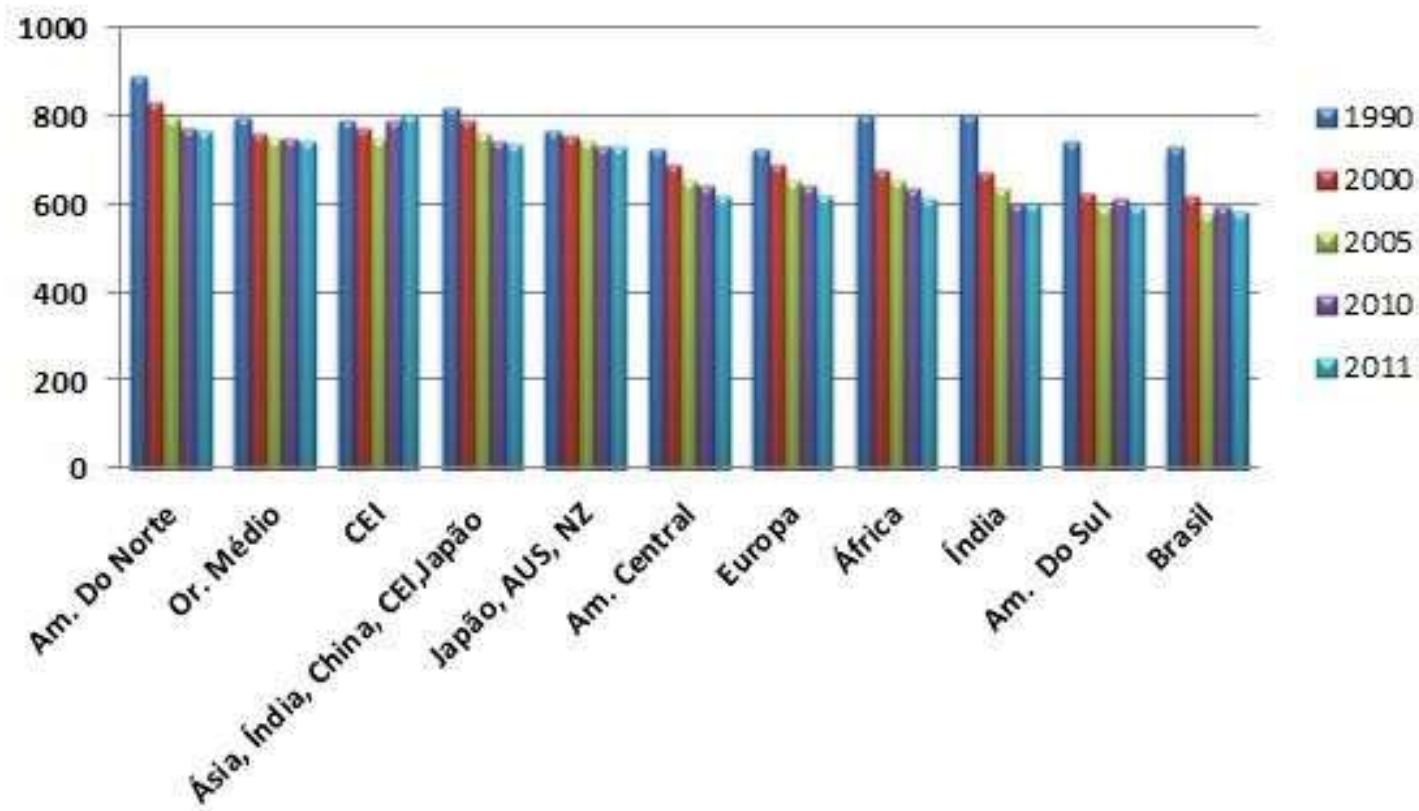

Fonte: Adapted from The Cement Sustainability Initiative - World Business Council for Sustainable Development.

O controle de emissão de $\mathrm{CO}_{2}$ na atmosfera é expressamente importante, pois ele é um dos gases que causam o efeito estufa e, assim, o aquecimento global.

Além da emissão de $\mathrm{CO}_{2}$ para a atmosfera, o uso de combustíveis fósseis está associado a outros impactos ambientais e na saúde humana. Podemos citar como exemplo o produto da queima de combustíveis de origem fóssil que é emitido ao se utilizar veículos automotores. Este produto carrega uma grande variedade de substâncias tóxicas, gerando efeitos negativos na saúde humana, afirma Teixeira et al. (2008). Além da acidificação de solo florestal e rios através da chuva ácida, do efeito estufa e do aquecimento global, Azuaga (2000) também afirma que os danos causados pela poluição atmosférica não são vistos somente em áreas onde ocorreu a emissão, pois ocorre a dispersão das partículas e dos gases por meio das correntes de ar.

Devido à emissão desses poluentes no ar, foi criada a Resolução do Conselho Nacional do Meio Ambiente (Conama) no 3/90, que define padrões de emissão para material particulado, metais pesados, cloretos, monóxido de carbono e dioxinas. Assim, as indústrias começaram a enviar esses poluentes provenientes das etapas do processo produtivo do 
cimento para chaminés contendo filtros e coletores com capacidade de retenção desses poluentes.

\section{UTILIZAÇÃO DE COMBUSTÍVEIS RENOVÁVEIS NO AQUECIMENTO DOS FORNOS}

Os combustíveis de biomassas apresentam concentrações de nitrogênio, enxofre e óxidos (produzidos durante o processo de combustão) significativamente menores do que as emissões produzidas pelos combustíveis fósseis. Relata-se que o nível de dióxido de carbono produzido a partir da combustão de biomassa não contribui para o aquecimento global. (CUIPING et al., 2004).

A alternativa proposta para reduzir a emissão de $\mathrm{CO}_{2}$ e diminuir a procura por combustíveis fósseis seria a utilização de biomassas naturais e artificiais que contêm energia e podem ser utilizadas pelas indústrias de cimento para geração da energia térmica. Estes podem ser produzidos com produtos vegetais, tais como cana-de-açúcar, mamona, canola, milho, entre outros.

O condicionamento do material residual antes da combustão também tem um grande impacto no desempenho do combustível, uma vez que materiais com um alto teor de umidade liberam menos energia líquida do que materiais com um baixo teor de umidade. Por este motivo, é indicado que seja removida a umidade antes da combustão. A saída de energia após a combustão é um parâmetro chave para determinar a viabilidade de um combustível (SCHINDLER et al., 2012).

Na Tabela 1, apresenta-se a diferença de energia fornecida pelo combustível com seu conteúdo de umidade natural e pelo combustível previamente seco (SCHINDLER et al., 2012).

Tabela 1- Energia aproximada dos típicos combustíveis alternativos, 2009 


\begin{tabular}{lcc}
\hline Combustivel Alternativo & $\begin{array}{c}\text { Valor aproximado de } \\
\text { energia do combustivel } \\
\text { com teor de umidade } \\
\text { natural } \\
\text { BTU/lb }(\mathrm{kcal} / \mathrm{kg})\end{array}$ & $\begin{array}{c}\text { Valor aproximado de } \\
\text { energia do combustível } \\
\text { seco }\end{array}$ \\
\hline Madeira & $2700(1500)$ & BTU/1b (kcal/kg) \\
Esterco de Gado & $1800(1000)$ & $6300(3500)$ \\
Bagaço & $4000(2200)$ & $6700(3700)$ \\
Palha de Trigo e Arroz & $4300(2400)$ & $7900(4400)$ \\
\hline
\end{tabular}

Tabela 2- Energia aproximada dos típicos combustíveis alternativos, 2009.

\begin{tabular}{lcc}
\hline Combustivel Alternativo & $\begin{array}{c}\text { Valor aproximado de } \\
\text { energia do combustivel } \\
\text { com teor de umidade } \\
\text { natural } \\
\text { BTU/lb }(\mathrm{kcal} / \mathrm{kg})\end{array}$ & $\begin{array}{c}\text { Valor aproximado de } \\
\text { energia do combustível } \\
\text { seco }\end{array}$ \\
$\begin{array}{l}\text { Restos de cana, casca de } \\
\text { arroz, folhas e resíduos } \\
\text { vegetais }\end{array}$ & $5400(3000)$ & $5400(3000)$ \\
$\begin{array}{l}\text { Cascas de coco, capim secoe } \\
\text { resíduos de culturas }\end{array}$ & $6300(3500)$ & $6300(3500)$ \\
$\begin{array}{l}\text { Cascas de Amendoim } \\
\text { Cascas de café e óleo de } \\
\text { palma }\end{array}$ & $7200(4000)$ & $7200(4000)$ \\
Cascas de algodão & $7600(4200)$ & $7600(4200)$ \\
\hline
\end{tabular}

Fonte: Adapted from Lechtenberg, 2009.

Atualmente não há critérios definidos para um material ser considerado um combustível. Este parâmetro é normalmente definido pelo produtor de cimento, de acordo com a necessidade do processo. Porém, há uma obrigatoriedade de assegurar que o conteúdo químico atende aos requisitos regulamentares de proteção ambiental (SCHINDLER et al., 2012). 
Geralmente os produtores de cimento escolhem as biomassas que irão ser utilizadas no processo com base no preço, disponibilidade, qualidade química do combustível, capacidade calorífica do combustível, o estado físico (líquido, sólido, semissólido ou em pó), umidade e conteúdo volátil (SCHINDLER et al., 2012).

Combustíveis provenientes de biomassas que possuem teor de umidade inferior a $10 \%$ são mais adequados para a conversão de energia térmica, enquanto as biomassas com maior teor de umidade produzem melhores resultados a partir de processos como a fermentação (CUIPING et al., 2004).

Há vantagens em utilizar os combustíveis alternativos, uma vez que são geralmente mais baratos do que os combustíveis fósseis disponíveis no mercado, pois em sua maioria são gerados a partir de resíduos que requerem apenas algum custo de processamento ou logística. A substituição por combustíveis alternativos tem como benefício a preservação de fontes de energia não renováveis, redução de resíduos e menor impacto ao meio ambiente (SCHINDLER et al., 2012).

Todavia, mudar para combustíveis alternativos apresenta vários desafios, uma vez que os mesmos têm características diferentes em comparação com os combustíveis convencionais, entre eles a má distribuição de calor, bloqueios nos ciclones pré-aquecedores, acúmulos nos dutos do forno e fornos empoeirados. A substituição do combustível requer custos iniciais de investimento associados ao ajuste ou substituição do queimador, estabelecimento de sistemas alternativos de distribuição de combustível e novas instalações de armazenamento de combustível (RAHMAN et al., 2013).

A biomassa que se equipara ao carvão mineral em termos energéticos é o carvão vegetal. Souza (2011) investigou o uso de carvão vegetal no sistema de aquecimento dos fornos de produção do clínquer de cimento Portland e, comparando o poder calorífico inferior (PCI) do carvão mineral (3.500 kcal $/ \mathrm{kg})$ com o do carvão vegetal $(6.400 \mathrm{kcal} / \mathrm{kg})$ observou-se que o valor para a biomassa é maior que o valor equivalente para o combustível não renovável. Esse resultado pode dar indícios de que a biomassa acarretaria em maior energia para o forno se comparada à energia que o carvão mineral pode oferecer.

Uma pesquisa realizada no ano de 2013 pela IEA Bioenergy Task 40, divisão especializada em bioenergia da Agência Internacional de Energia, fez um levantamento de dados e concluiu que, em 2009, o Brasil foi o país que mais utilizou biomassa na produção de energia, sendo $16 \%$ do uso mundial no setor. 


\section{BIOMASSAS DE ORIGEM AGRÍCOLA}

A partir de uma pesquisa bibliográfica, os poderes caloríficos de algumas biomassas de origem agrícola foram avaliados e comparados com o poder calorífico do carvão mineral para verificar a viabilidade de utilização em aquecimento de fornos da indústria cimenteira. Os dados são apresentados na Tabela 3. 
Tabela 3 - Poder calorífico das respectivas biomassas de origem agrícola estudadas e suas fontes, 2019.

\begin{tabular}{|c|c|c|}
\hline Biomassa & $\begin{array}{l}\text { Poder calorífico inferior } \\
\qquad(\mathrm{kJ} / \mathrm{kg})\end{array}$ & Fonte \\
\hline Palha de cana-de-açúcar & 17860,67 & SANTOS, et al., 2018 \\
\hline Bagaço de cana-de-açúcar & 16826,4 & $\begin{array}{l}\text { OLIVEIRA, A; } \quad \text { F. } \\
\text { STELLA, 2014. }\end{array}$ \\
\hline Fibra de coco & 18370 & BARBOSA et al, 2014. \\
\hline & & IBERO MASSA \\
\hline Poda de macieira & 18217 & $\begin{array}{l}\text { FLORESTAL LTA. Projeto } \\
\mathrm{n}^{\circ} 34001.2014\end{array}$ \\
\hline Poda de oliveira & 18117 & $\begin{array}{l}\text { IBERO MASSA } \\
\text { FLORESTAL LTA. Projeto } \\
\mathrm{n}^{\circ} 34001.2014\end{array}$ \\
\hline Poda de amendoeira & 18003 & $\begin{array}{l}\text { IBERO MASSA } \\
\text { FLORESTAL LTA. Projeto } \\
\mathrm{n}^{\circ} 34001.2014\end{array}$ \\
\hline Poda de fruteiras & 14654 & $\begin{array}{l}\text { IBERO MASSA } \\
\text { FLORESTAL LTA. Projeto } \\
\mathrm{n}^{\circ} 34001.2014\end{array}$ \\
\hline Cana de girassol & 13089 & $\begin{array}{l}\text { IBERO MASSA } \\
\text { FLORESTAL LTA. Projeto } \\
\mathrm{n}^{\circ} 34001.2014\end{array}$ \\
\hline Sabugo do milho & 18727,58 & VALE et al., 2013. \\
\hline Palha do milho & 18258,976 & VALE et al., 2013. \\
\hline Folha do milho & 18263,16 & VALE et al., 2013. \\
\hline Caule do milho & 18192,032 & VALE et al., 2013. \\
\hline Casca de Eucalyptus & 17535,14 & CANTIZANI et al., 2016. \\
\hline Casca de coco & 16736,98 & $\begin{array}{l}\text { Catálogo da Alfa Laval } \\
\text { Industries }\end{array}$ \\
\hline Casca de arroz & 13807,18 & $\begin{array}{l}\text { Catálogo da Alfa Laxal } \\
\text { Industries }\end{array}$ \\
\hline Casca de arroz & 13388,8 & CARDOSO, 2012. \\
\hline
\end{tabular}

Fonte: Criação das autoras.

Revinter, v. 12, n. 02, p. 47-65, jun. 2019.

Página $65 \mid 65$ 
O poder calorífico do carvão mineral é de $14644 \mathrm{KJ} / \mathrm{kg}(3.500 \mathrm{kcal} / \mathrm{kg})$. Portanto, toda biomassa que apresentar um valor maior de poder calorífico seria uma boa sugestão, considerando apenas termos energéticos, para a substituição do carvão mineral nos fornos.

A seguir, serão discutidos dados de viabilidade, em termos econômicos e energéticos, para cada uma das biomassas citadas como alternativa ao uso do carvão mineral em aquecimento de fornos da indústria cimenteira.

\section{a. Podas}

As podas realizadas em árvores frutíferas, como macieiras, amendoeiras e oliveiras, têm como objetivo manter a árvore saudável para que sua produção seja intensa, sendo assim um fator fundamental. Porém, os galhos provenientes da poda não possuem destino que vise seu reaproveitamento em bases energéticas e, ao observar seu poder calorífico (14000 a 18000 $\mathrm{kJ} / \mathrm{kg}$ ), pode-se inferir que tal recurso é viável em termos energéticos.

A viabilidade deste recurso também é algo para ser observado, pois são realizadas podas em árvores frutíferas com grande frequência. Essa prática é realizada desde os primeiros anos das árvores e promovem grande benefício para as mesmas, portanto os volumes de podas de diferentes árvores localizadas em uma mesma região podem ser bem significativos. Para o agricultor, a poda é um resíduo do processo de cultivo, portanto poderia ser utilizado com a finalidade de manter os fornos aquecidos. É possível misturar vários tipos de poda, de modo que o poder calorífico final seja suficiente para a aplicação.

b. Caule, folha, sabugo e palha do milho

A colheita do milho gera quatro tipos de resíduos: a palha da espiga, o sabugo, a folha e o caule, que geralmente são deixados no campo para a ciclagem de nutrientes. Quando se trata do sabugo e da palha da espiga, estes são resíduos que podem ser gerados no processamento industrial quando o objetivo é a produção de milho verde em conserva e, em tal caso, com melhores possibilidades de serem utilizados para a geração de energia, afirmam Vale, Dantas e Zambrzycki (2013), que investigaram o poder energético dos resíduos da cultura do milho (Zea mays) produzidos em Brasília-DF, na Fazenda Água Limpa, da Universidade de Brasília. Observando o poder calorífico disponibilizado na Tabela 1, observa-se para o caule o valor de $18192,032 \mathrm{~kJ} / \mathrm{kg}$; para a folha, $18263,16 \mathrm{~kJ} / \mathrm{kg}$; para o sabugo, $18727,58 \mathrm{~kJ} / \mathrm{kg}$; e para a palha, $18258,976 \mathrm{~kJ} / \mathrm{kg}$. 
$\mathrm{Na}$ literatura podem ser encontrados outros trabalhos que investigam o poder calorífico associado ao milho, como Raveendran, Ganesh e Khilar (1995); Koopmans e Koppejan (1997); Salazar, Silva e Silva (2005); Cortez, Lora e Ayarza (2008); Protásio, Bufalino e Tonoli (2011); Silva, Bentes e Medrado (2011).

\section{c. Casca da mandioca}

Ao avaliar fatores culturais e econômicos, o sistema produtivo da mandioca se apresenta de modo diversificado no país, podendo ser classificado em três tipos: unidade familiar, unidade doméstica e unidade empresarial. Em todas as unidades, há geração de resíduos que necessitam de um manejo adequado. Em peso seco, para cada tonelada de raiz de mandioca processada na produção de farinha, obtém-se de 102 a 153 kg de resíduo sólido (BRINGHENTI; CABELLO, 2005).

Diversos estudos vêm sendo realizados com o objetivo de reaproveitar a casca da mandioca, entre eles podemos citar seu uso na compostagem (TEIXEIRA et al., 2011) e seu processamento com a finalidade de alimentar ovinos (FARIA et al., 2011). Quando se trata de seu uso na compostagem não foi observada uma diferença na atividade microbiana e na fertilidade do solo ao longo do experimento (90 dias), ou seja, a casca da mandioca possui baixa influência nas propriedades do solo. Já em sua utilização como alimento para ovinos, foi sugerido melhorar a conservação e o aproveitamento nutricional.

Uma alternativa de reaproveitamento da casca de mandioca seria sua utilização em fornos para produção de cimento. Alves (2014) avaliou em sua dissertação o potencial energético de resíduos de produção agrícola provenientes do beneficiamento da mandioca e do milho. Foram quantificados resíduos provenientes do milho e da casca da mandioca produzidos no estado de Alagoas, realizando testes físico-químicos com o objetivo de determinar o poder calorífico dos resíduos. Para a casca da mandioca, foi obtido o valor de $16790 \mathrm{KJ} / \mathrm{kg}$.

O valor obtido de poder calorífico para a casca da mandioca no trabalho de Alves (2014) é maior em comparação ao do carvão mineral (14644 KJ/kg). Ou seja, em termos energéticos, a utilização de tal combustível renovável seria viável.

d. Casca de arroz, coco e eucalyptus

Na safra de 2009/2010, foram colhidas 11,26 milhões de toneladas de arroz, sendo o Brasil o nono produtor mundial, de acordo com dados disponibilizados pelo Ministério da 
Agricultura, Pecuária e Abastecimento. A casca de arroz corresponde a 22\% do peso do grão e, na safra de 2009/2010, foram gerados 2,48 milhões de toneladas deste resíduo. É estimado que $15 \%$ do total de casca de arroz seja destinado à secagem do arroz e mais $15 \%$ não possa ser aproveitado por ser originário de pequenas indústrias dispersas, o que acaba inviabilizando sua utilização. Dessa formam, restam 1,74 milhões de toneladas de casca de arroz que podem ser reutilizadas. Sendo o poder calorífico da casca de arroz equivalente à 13388,8 kJ/kg, 1,74 milhões de toneladas de casca de arroz geram $2,3 \times 10^{13} \mathrm{~kJ}$; para gerar a mesma quantidade de energia com o carvão mineral, são necessários 1,57 milhões de toneladas de carvão mineral, ou seja, 0,17 toneladas a mais de casca de arroz.

O cultivo de coqueiro no Brasil é distribuído em praticamente todo o território nacional, em cerca de 280 mil, sendo produzido o equivalente a dois bilhões de frutos. De acordo com pesquisas realizadas pela EMBRAPA (Empresa Brasileira de Pesquisa Agropecuária), em produção agrícola municipal, entre os 10 maiores estados produtores de coco do Brasil, 7 são da região Nordeste, visto que a liderança da produção é do Estado da Bahia, seguido de Sergipe e Ceará. Estes estados juntos correspondem a mais de $50 \%$ da produção nacional de coco nacional (CUENCA; MARTINS; JESUS JUNIOR, 2011).

No Brasil, o mercado de coco-verde tem crescido nos últimos anos. A casca do coco é considerada um subproduto existente após o uso por parte do consumidor final ou do uso industrial. Tal subproduto tem como destino, em sua grande parte, lixões e aterros sanitários, visto que $80 \%$ a $85 \%$ do peso bruto do coco verde é considerado lixo (ROSA et al.,2001). Logo, tal resíduo gera custos e impactos para a sociedade (CARDOSO; GONÇALEZ, 2016), levando em conta que a casca de coco verde possui longo tempo de decomposição (oito anos) (CARRIJO; LIZ; MAKISHIMA, 2002).

Murray e Price (2008) avaliaram o uso de combustíveis alternativos para a produção de cimento através da análise das características do combustível e viabilidade para seu uso na indústria do cimento chinesa. Entre as biomassas citadas como já utilizadas em fornos de cimento está a casca do coco, que apresenta um poder calorífico de 16736,98 kJ/kg. Esse valor é maior que o poder calorífico encontrado no carvão mineral (14644 kJ/kg), viabilizando, em termos energéticos, a substituição do combustível fóssil.

Há alguns anos, as atividades de exploração florestal tinham como único objetivo, na maioria de atividades, a madeira para celulose, lâminas, chapas e etc., e os resíduos que possuíam chance de conversão para energia eram deixados no local (COUTO; BRITO, 1980). 
Após a exploração madeireira, são deixados, em média, $70 \mathrm{~m}^{3} / \mathrm{ha}$ de resíduos que possuem diâmetros superiores a $10 \mathrm{~cm}$ (BARROS, 2008).

Cascas de Eucalyptus permanecem nas florestas após a colheita da madeira. Realizando a caracterização de tal resíduo como uma possível fonte de energia, foi obtido seu poder calorífico de 17535,14 kJ/kg (CANTIZANI et al., 2016). Como o poder calorífico encontrado é maior que o poder calorífico do carvão mineral (14644 KJ/kg), em termos energéticos, a substituição seria favorável. De acordo com Brito et al. (1979), 1 hectare de floresta de Eucalyptus saligna, com 8 anos de idade em termos de casca, seria o equivalente a 2,4 toneladas de óleo combustível e 6,3 toneladas de carvão vapor médio.

Na Tabela 4, são apresentados os custos relacionados às lascas de madeira e ao carvão mineral, observando-se que, embora o sistema convencional utilizando o carvão mineral como combustível exija menor capital inicial, os sistemas de queima de lascas de madeira trazem economias substanciais em um período de tempo significativamente menor (Maker, 2004).

Tabela 4 - Custo comparativo dos combustíveis para lascas de madeira, 2004.

\begin{tabular}{lccc}
\hline Combustivel & $\begin{array}{c}\text { Faixa de preço do } \\
\text { combustivel por } \\
\text { tonelada }\end{array}$ & $\begin{array}{c}\text { Custo bruto do } \\
\text { combustivel por } \\
\text { MBTU }\end{array}$ & $\begin{array}{c}\text { Custo líquido do } \\
\text { combustivel por } \\
\text { MBTU }\end{array}$ \\
\hline Carvão & $\$ 100-\$ 150$ & $\$ 4.00-\$ 6.00$ & $\$ 5.70-\$ 8.55$ \\
Lascas de madeira & $\$ 20-\$ 34$ & $\$ 2.00-\$ 3.45$ & $\$ 3.10-\$ 5.30$ \\
\hline
\end{tabular}

Fonte: Adapted from Marker 2004.

OBS: MBTU - 1 Million BTUs.

e. Bagaço da cana-de-açúcar e palha da cana-de-açúcar

Existe uma indagação a respeito da interferência da produção do etanol celulósico na cogeração (geração concomitante de energia térmica e mecânica, a partir de um mesmo combustível), já que atualmente o bagaço tem como destino a queima em caldeiras gerando energia e, muitas vezes, em quantidade maior que a quantidade que a usina necessita, sendo então passível de comercialização. Grande parte da palha ainda é deixada no campo, todavia, existem estudos para discutir se sua queima é viável, com a possibilidade do aumento da produção de energia gerada atualmente (ROVIERO et al., 2018). 
O potencial de geração de energia elétrica pelo setor sucroalcooleiro está relacionado de modo direto à tecnologia empregada, pois temos como consequência os custos unitários ( $\mathrm{R} \$ / \mathrm{kW}$ instalado), sendo influenciados pelo efeito escala. Leva-se em conta o tipo de caldeira utilizada para a queima (caldeiras de pressão mais elevada - 40 a 100 bar), tanto como o emprego de turbinas de múltiplo estágio, podem elevar, de modo significativo, a eficiência energética do processo (ROVIERO et al., 2018).

Em termos de poder calorífico, Oliveira (2014) realizou uma avaliação energética da biomassa do bagaço da cana-de-açúcar em diferentes indústrias sucroenergéticas e, para o poder calorífico do bagaço da cana-de-açúcar, encontraram o correspondente a $16826,40 \mathrm{~kJ} / \mathrm{Kg}$. Comparando tal valor com o valor adotado como base para o poder calorífico do carvão mineral (14644 kJ/kg), está acima do mesmo. Logo, o bagaço da cana poderia substituir o carvão mineral nos fornos para produção de clínquer, levando-se em conta somente o poder calorífico dos combustíveis.

Um dos principais resíduos da cana de açúcar é a palha da mesma, que é composta por ponteiros e folhas. Uma prática comum e econômica para as usinas era a queima da palha quando se encontrava ainda no campo, possuindo como objetivo o aumento do rendimento da colheita manual. Porém, tal prática não é mais aceita pelo fato de termos uma melhora na tecnologia empregada na colheita e por leis que proíbem tal ato (PADILLA et al., 2016).

Um estudo com o objetivo de potencializar o uso de resíduos para fins energéticos foi feito por Santos et al. (2018) ao analisar aspectos físicos da produção de combustível sólido a partir da palha da cana de açúcar e braquiária. O poder calorífico encontrado para a palha da cana de açúcar corresponde a 17860,67 kJ/kg e, ao compararmos tal valor com o valor correspondente ao carvão mineral $(14644 \mathrm{~kJ} / \mathrm{kg})$ vemos que o valor agregado ao combustível renovável é maior, sendo assim, em termos caloríficos a substituição do carvão mineral por palha da cana de açúcar seria viável.

\section{CONCLUSÃO}

Em termos energéticos, todos os combustíveis de origem vegetal analisados, exceto a casca de arroz, possuem poder calorífico superior ao poder calorífico do carvão mineral. Analisando puramente em termos energéticos, todas as alternativas de substituição seriam 
viáveis. Todas as biomassas citadas têm como característica em comum serem resíduos de processos necessários para suprir demandas de mercado.

A biomassa que mais se destaca seja pelo poder calorífico, dificuldade de reciclagem e decomposição, além de sua alta disponibilidade, seria a casca do coco. Como há pesquisas que citam a mesma como um possível combustível renovável para a finalidade a qual o trabalho foi escrito, tal biomassa se tornou a mais interessante.

Para a substituição gradual dos combustíveis fósseis pelos alternativos, uma mistura entre esses combustíveis em composições adequadas poderia ser utilizada para produzir a energia térmica necessária na indústria de cimento.

Apesar de observada a possível viabilidade do uso dos combustíveis fósseis, mais pesquisas necessitam ser realizadas, em termos de teor de cinzas, umidade e peso, para garantir a boa eficiência dos fornos de cimento quando se trata da produção de clínquer.

\section{REFERÊNCIAS BIBLIOGRÁFICAS}

ALFA LAVAL AALBORG INDUSTRIES. Catálogo de poder calorífico inferior. Petrópolis, RJ. Disponível em: http://www.aalborg-industries.com.br/downloads/poder-calorifico-inf.pdf. Acesso em: 23 de março de 2018.

ALVES, D. A. de H. Avaliação do potencial energético de resíduos de produção agrícola provenientes do beneficiamento da mandioca e do milho. 2014. 80 f. Dissertação (Mestrado em Engenharia Química) - Unidade Federal de Alagoas. Centro de Tecnologia. Maceió, 2014. AZUAGA, D. Danos ambientais causados por veículos leves no Brasil. Dissertação (Mestrado em Ciências em Planejamento Energético) - Universidade Federal do Rio de Janeiro - UFRJ, 2000. BARBOSA, I. R. et al. Caracterização do potencial energético de biomassas. In: ANAIS DO CONGRESSO BRASILEIRO DE ENGENHARIA QUíMICA, 2016, . Anais eletrônicos...Campinas, GALOÁ, $2018 . \quad$ Disponível em: $<$ https://proceedings.science/cobeq/cobeq-2016/papers/caracterizacao-do-potencial- energetico-debiomassas> Acesso em: 10 mar. 2019.

BARROS, P.L.C de. Resíduos florestais e as implicações da reserva legal. Disponível em: </www.aeapa.com.br/Doc/TEXTO_LIBERAL.doc.AMAZÔNIA/>. Coordenado por Inocêncio de Sousa Gorayeb - Belém: RM Graph, 2008.: A Mata que vira carvão, por Paulo Contente, Prof. da UFRA 273 - 276p.

BRAGA, B. et al. Introdução à engenharia ambiental. 2. ed. São Paulo: Pearson Prentice Hall, 318 p., 2005. 
BRINGHENTI, L.; CABELLO, C. Qualidade do álcool produzido a partir de resíduos amiláceos da agroindustrialização da mandioca. Revista Energia na Agricultura, Botucatu, v. 20, n. 4, p. 36-52, 2005.

BRITO, J. O. et al. Avaliação das características dos resíduos de exploração florestal do eucalipto para fins energéticos. Circular Técnica IPEF, Piracicaba, n. 62, 1979.

CANTIZANI, P. A. et al. Estudo comparativo do poder calorífico da biomassa adquirida de terceiros com a casca de Eucalyptus descartada nas florestas para geração de energia térmica e elétrica.

Integrada, Revista Científica FACOL/ISEOL, São Paulo, 1. ed., p. 240-251, 2016.

CARDOSO, B. M. Uso da Biomassa como Alternativa Energética. 2012. 94 f. Trabalho de

Conclusão de Curso (Bacharel em Engenharia Elétrica) - Universidade Federal do Rio de Janeiro -

UFRJ, Rio de Janeiro, 2012.

CARDOSO, M. S.; GONÇALEZ, J. C. Aproveitamento da casca do coco-verde (Cocos nucifera L.) para produção de polpa celulósica. Ciência Florestal, Santa Maria, v. 26, n. 1, p. 321-330, jan.-mar., 2016.

CARRIJO, O. A., LIZ, R. S.; MAKISHIMA, N. Fibra da casca de coco verde como substrato agrícola. Horticultura Brasileira, v. 20, n. 4, p. 533-535. 2002.

CORRÊA, H. Raspa de mandioca em nível de fazenda. Inf. Agropec, Belo Horizonte, v. 13, p. 58-61, 1987.

CORTEZ, L. A. B.; LORA, E. E. S.; AYARZA, J. A. C. Biomassa no Brasil e no mundo.

In: Biomassa para energia. Campinas: Ed. Unicamp, 2008.

COUTO, H. T.Z.; BRITO, J. O. Inventário de resíduos florestais. Série Técnica IPEF, Piracicaba, v. 1, n. 2, p. A.1-A.13, jul.1980.

CUENCA, M. A.; MARTINS, C. R.; JESUS JUNIOR, L. A. Estatística da Produção de Coco.

$2011 . \quad$ Disponível em:

</http://www.agencia.cnptia.embrapa.br/gestor/coco/arvore/CONT000fo7hz6ox02wyiv80656

10d6ky3ary.html/>. Acesso em: 11 jan. 2019.

CUIPING, L. et al. Chemical Elemental Characteristics of Biomass Fuels In China. Journal of

Biomass \& Bioenergy, Amsterdam, v. 27, n. 2, p. 119-130, 2004.

FARIA, P. B. et al. Processamento da casca de mandioca na alimentação de ovinos: desempenho, características de carcaça, morfologia ruminal e eficiência econômica. R. Bras. Zootec., Piracicaba, v.40, n.12, p.2929-2937, 2011.

GIUSTI, R. J. Panorama do Coprocessamento Brasil 2016. Associação Brasileira de Cimento Portland, São Paulo, 01 dez. 2016. Disponível em: < http://coprocessamento.org.br/destaquehome/panorama-do-coprocessamento-brasil-2015>. Acesso em: 7 set. 2017.

IBERO MASSA FLORESTAL LTA. Projeto $n^{\circ}$ 34001: Estudo do potencial energético de calor de cada biomassa/resíduo agrícola e vegetal. ENGASP. São Paulo, 2014.

JÚNIOR, R. A. R. Análise da viabilidade do aproveitamento da palha da cana de açúcar para cogeração de energia numa usina sucroalcooleira. 2009. 164 f. Dissertação (Mestrado em Engenharia Mecânica) - Universidade Estadual Paulista, Faculdade de Engenharia de Ilha Solteira UNESP, Ilha Solteira. 2009.

KIHARA, Y.; VISEDO, G. A indústria do cimento e o desenvolvimento do Brasil. Associação Brasileira de Cimento Portland, 2014. Disponível em :< 
http://www.abcp.org.br/cms/imprensa/a-industria-do-cimento-e-o-desenvolvimento-do- brasil/> . Acesso em: 7 set. 2017.

KOOPMANS, A.; KOPPEJAN, J. Agricultural and forest residues: generation, utilization and availability. In: REGIONAL CONSULTATION ON MODERN APPLICATIONS OF

BIOMASS ENERGY, Malasia: FAO: Kuala Lumpur, 23 p. 1997.

LECHTENBERG, D. The Use of Alternative Fuels in the Cement Industry of Developing Countries an opportunity to reduce production costs? Cement International 7, no. 2:66- 70, 2009.

MARQUES, J. A. et al. Avaliação da mandioca e seus resíduos industriais em substituição ao milho no desempenho de novilhas confinadas. R. Bras. Zootec., Piracicaba, v. 29, n. 5, p. 1528-1536, 2000. MURRAY, A.; PRICE, L. Use of Alternative Fuels in Cement Manufacture: Analysis of Fuel Characteristics and Feasibility for Use in the Chinese Cement Sector. Ernest Orlando Lawrence Berkeley National Laboratory: Berkeley, 2008.

OLIVEIRA, A. F. S. Avaliação energética da biomassa do bagaço da cana-de-açúcar em diferentes indústrias sucroenergéticas. 2014. 80 f. Dissertação (Mestrado Profissional em Produção) - Instituto Tecnológico de Aeronáutica - ITA, São José dos Campos. 2014.

PADILLA, E. R. D. et al. Produção e Caracterização Físico-Mecânica de Briquetes de Fibra de Coco e Palha de Cana -de-Açúcar. Revista Virtual Química, Niterói, v.8, n.5, p.1334- 1346, 2016.

PROTÁSIO, T. P.; BUFALINO, L.; TONOLI, G. H. D. Relação entre o poder calorífico superior e os componentes elementares da biomassa. Pesq. flor. bras., Colombo, v. 3, n. 66, p. 113-122, 2011.

RAHMAN, A. et al. Impact of alternative fuels on the cement manufacturing plant performance: an overview. Procedia Engineering, Amsterdã, v. 56, p. 393 - 400, 2013.

RAVEENDRAN, K.; GANESH, A.; KHILAR, K. C. Influence of mineral matter on biomass pyrolysis characteristics. Fuel, Amsterdam, v. 74, p. 12-22, 1995.

ROSA, M. F. et. al. Caracterização do pó da casca de coco verde usado como substrato agrícola. Comunicado Técnico, 54. Fortaleza: Embrapa Agroindústria Tropical, p. 6. 2001.

ROVIERO, J. P. et al. Poder calorífico da palha e do bagaço de cana após pré-tratamento e hidrólise. In: SIMPÓSIO DE TECNOLOGIA AMBIENTAL E DE BIOCOMBUSTÍVEIS.

CIENCIA \& TECNOLOGIA, 2018, Jaboticabal. Anais..., Jaboticabal: Fatec-JB, 2018, v. 10, p. 37 42, 2018.

SALAZAR, R. F. S.; SILVA, G. L. P.; SILVA, M. L. C. P. Estudo da composição da palha de milho para posterior utilização como suporte na preparação de compósitos. In: VI CONGRESSO

BRASILEIRO DE ENGENHARIA QUÍMICA EM INICIAÇÃO

CIENTIFICA, 2005, Lorena. Anais..., Lorena: Faculdade de Engenharia Química de Lorena (FAENQUIL), 2005. p.7.

SANTOS, L. R. O. et al. Produção de combustíveis sólidos a partir da palha da cana-de- açúcar e braquiária. Revista Brasileira de Energias Renováveis, Palotina, v.7, n.2, p.266- 279, 2018. 
SCHINDLER, A. K. et al. Alternative Fuel for Portland Cement Processing. Auburn University (U.S. Department of Energy), set. 2012.

SCHMIDT, M. et. al. Blended Cements in 'Innovations in Portland Cement Manufacturing' (Ed.) JI Bhatti, F MacGregor, SH Kosmatka, Portland Cement Association, Skokie, Illinois. p. 1107-1148, 2004.

SILVA, A. L. F. Compostagem de casca de mandioca e seus efeitos sobre as propriedades químicas e biológicas do solo. 2010. 98 f. Dissertação (Mestrado em Produção Vegetal) Universidade Federal do Acre - UFAC, Acre. 2010.

SILVA, A. M.; BENTES, M. A.; MEDRADO, S. B. Estudo da utilização da biomassa em substituição parcial ao carvão mineral na fabricação do coque na coqueira da CSN. Revista Tecnologia em Metalurgia e Materiais, São Paulo, v. 5, n. 1, p.40-45, 2011.

Sindicato Nacional da Indústria do Cimento. Relatório anual 2010. Rio de Janeiro, 2010. Sindicato Nacional da Indústria do Cimento. Relatório anual 2012. Rio de Janeiro, 2012. SOUZA, B. D. Estudo do uso de carvão vegetal no sistema de aquecimento dos fornos de produção do clínquer de cimento portland. Resumo do relatório PIBIC - Pontifícia Universidade Católica, Departamento de Engenharia de Materiais - PUC-RIO, Rio de Janeiro, 2011.

TEIXEIRA, E. C; FELTES, S; SANTANA, E. R. R. Estudo Das Emissões De Fontes Móveis Na Região Metropolitana De Porto Alegre, Rio Grande Do Sul. Química Nova, São Paulo, v. 31, p. 244, 2008.

TEIXEIRA, S. T. et al. Reciclagem Agrícola de Manipueira e Casca de Mandioca. Comunicado técnico, 179. Rio Branco, AC: Embrapa Acre, p. 6. 2011.

VAKKILAINEN, E.; KUPARIEN, K.; HEINIMÖ, J. Large Industrial Users of Energy Biomass. IEA Bioenergy. Task 40: Sustainable International Bioenergy Trade. Lappeenranta University of Technology, Finlândia, 2013.

VALE, A. T.; DANTAS, V. F. S.; ZAMBRZYCKI, G. C. Potencial Energético dos Resíduos da Cultura do Milho (Zea mays). Evidência, Joaçaba, v. 13, n. 2, p. 153-164, jul./dez 2013. 